\title{
Cell lineage analysis of the avian neural crest
}

\author{
MARIANNE BRONNER-FRASER ${ }^{1}$ and SCOTT E. FRASER ${ }^{2}$ \\ ${ }^{1}$ Developmental Biology Center, University of California, Irvine, CA 92717, USA \\ ${ }^{2}$ Division of Biology, Beckman Institute 139-74, California Institute of Technology, Pasadena, CA 91125, USA
}

\section{Summary}

Neural crest cells migrate extensively and give rise to diverse cell types, including cells of the sensory and autonomic nervous systems. A major unanswered question concerning the neural crest is when and how the neural crest cells become determined to adopt a particular fate. We have explored the developmental potential of trunk neural crest cells in avian embryos by microinjecting a vital dye, lysinated rhodamine dextran (LRD), into individual cells within the dorsal neural tube. We find that premigratory and emigrating neural crest cells give rise to descendants with distinct phenotypes in multiple neural crest derivatives. These results are consistent with the idea that neural crest cells are multipotent prior to their emigration from the neural tube and become restricted in phenotype after emigration from the neural tube either during their migration or at their sites of localization. To determine whether neural crest cells become restricted during their migration, we have microinjected individual trunk neural crest cells with dye shortly after they leave the neural tube or as they migrate through the somite. We find that a majority of the clones derived from migrating neural crest cells appear to be multipotent; individual migrating neural crest cells gave rise to both sensory and sympathetic neurons, as well as cells with the morphological characteristics of Schwann cells, and other nonneuronal cells. Even those clones contributing to only one neural crest derivative often contained both neurofilament-positive and neurofilament-negative cells. These data demonstrate that migrating trunk neural crest cells, like their premigratory progenitors, can be multipotent. They give rise to cells in multiple neural crest derivatives and contribute to both neuronal and non-neuronal elements within a given derivative. Thus, restriction of neural crest cell fate must occur relatively late in migration or at the final destinations.

Key words: developmental potential, intracellular injection, determination, cell fate.

\section{Introduction}

The vertebrate neural crest is a cell population which arises during neurulation as the neural folds close to form the neural tube. Neural crest cells migrate away from the neural tube, sometimes traversing considerable distances to form a wide array of derivatives in a variety of sites. Some aggregate to form sensory, sympathetic and parasympathetic ganglia, and chromaffin cells of the adrenal medulla; others form melanocytes in the skin, enteric neurons in the gut, and connective tissue of the face (LeDouarin, 1982). As a population along the neural axis, the neural crest is regionalized: cells derived from different axial levels contain different subsets of cells that follow distinct migratory pathways and give rise to a varied and sometimes non-overlapping array of progeny. The subdivisions of the neural crest have been classified (from rostral to caudal) as cranial, vagal, trunk, and sacral (LeDouarin, 1982).

The pathways of neural crest cell migration have been well-documented using a variety of cell markers. In the trunk of the avian embryo, neural crest cells migrate along two predominant pathways after leaving the neural tube. Early migrating cells move ventrally through the rostral half of each somitic sclerotome and toward the dorsal aorta (Rickmann et al. 1985; Bronner-Fraser, 1986) to form dorsal root and sympathetic ganglion cells, as well as adrenomedullary cells. Later migrating cells move beneath the ectoderm where they eventually form pigment cells (Serbedzija et al. 1989).

Neural crest cells have several unique properties that make them a useful cell type for studying cell lineage in the developing embryo. (1) They migrate extensively along well-characterized 'pathways'. (2) They give rise to numerous and diverse derivatives. (3) They are accessible to surgical and immunological manipulations during initial and several later stages in their development.

\section{The issue of neural crest cell lineage}

A major question concerning the developmental potential of neural crest cells is when and how they become 
A

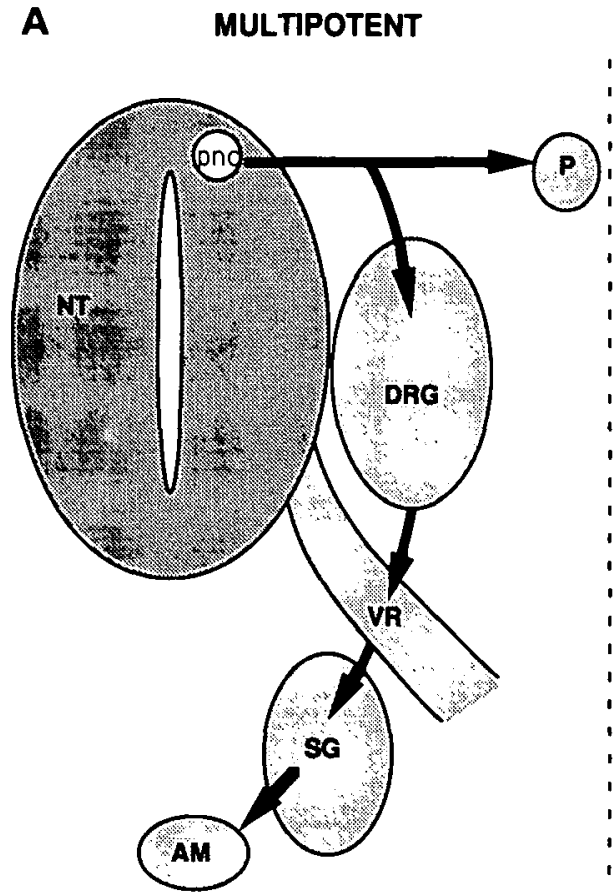

B PREDETERMINED

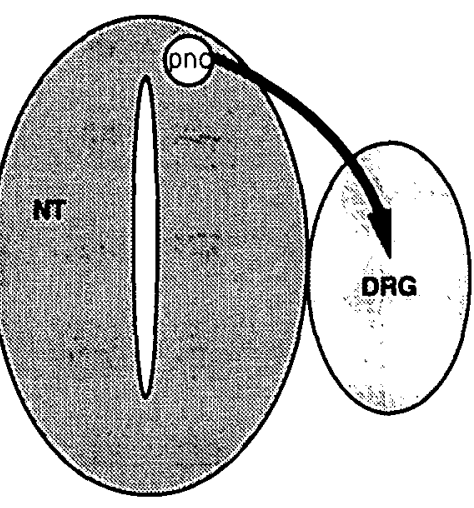

Fig. 1. Schematic diagram illustrating two possible mechanisms to explain neural crest cells lineage in the trunk. (A) Neural crest cells may be 'multipotent' such that an individual premigratory neural crest cell (pnc) has the ability to give rise to multiple neural crest derivatives such as pigment cells ( $p$ ), dorsal root ganglion (DRG) cells, Schwann cells in the ventral root.(VR), sympathetic ganglion (SG) cells, and cells in the adrenal gland (AM).

(B) Alternatively, neural crest cells may be predetermined to give rise to a single cell type, such as a sensory neuron in DRG. committed to a particular fate. At the onset of their migration, neural crest cells at all axial levels appear morphologically similar. After their migratory phase, they differentiate into widely varied cell types, as different as pigment cells, neurons and cartilage. How is diversity generated within this apparently homogeneous population, both at a single axial level and at different axial levels? Two extreme scenarios have been proposed to account for the diversity of neural crest derivatives. One possibility is that the neural crest is a homogeneous population of multipotent cells, each with identical developmental potential and able to give rise to a large range of phenotypes (Fig. 1A). A multipotent cell, by definition, has the ability to make a different set of descendant cell types in different conditions. Such multipotent cells might migrate randomly and differentiate according to instructive cues encountered along their migratory pathway or at their final sites of localization. A second and converse possibility is that the neural crest comprises a heterogeneous mixture of 'predetermined' (unipotent) cells, each fated to become a given derivative (Fig. 1B). These cells could migrate in a directed fashion to their proper locations and differentiate according to their prescribed fate; alternatively, they could migrate randomly and those localized in inappropriate sites must either fail to differentiate or die. A third possibility reconciles these two converse views by proposing that neural crest cells represent a mixture of multipotent and predetermined cells.

\section{Methods for studying cell lineage}

It is necessary to understand an individual cell's lineage in order to distinguish the relative importance of the external environment from the cell's inherent developmental program in the choice of cell fate. A knowledge of individual neural crest cell lineage requires an examination of the neural crest at a single cell level and at prescribed times in development. The developmental potential of individual neural crest cells has been studied by two predominant experimental approaches: (1) isolating single cells in tissue culture and (2) marking individual cells within the living embryo.

Individual neural crest cells have been cultured successfully by a number of investigators (c.f SieberBlum and Cohen, 1980; Bronner-Fraser et al. 1980; Baroffio et al. 1988; Sieber-Blum, 1989). These experiments have shown that single trunk neural crest cells can give rise to adrenergic, sensory-like, and pigmented cells; such data support the idea that some premigratory neural crest cells are multipotent (Sieber-Blum, 1989). Cranial neural crest cells also have diverse developmental potential; some clones derivated from single cultured cells contain only neural cells whereas others have mixed derivatives, as diverse as neurons and cartilage (Baroffio et al. 1988, 1991). However, it is possible that neural crest cells cloned in vitro may behave differently in culture than they do in the intact embryo. Due to unpredictable influences of the tissue culture environment, these data can be taken as only a suggestion of the potential of neural crest cells in situ. Therefore, a prospective cell lineage analysis in the intact embryo is an important complement to in vitro experiments.

Marking individual neural crest cells in situ so that their descendants can be uniquely identified is an effective means of testing their developmental potential. Recently, two methods have emerged for the study of cell lineage in the developing nervous system: (1) microinjection of individual cells with lineage tracers 
such as lysinated fluorescent dextran (Gimlich and Braun, 1986) or horseradish peroxidase (HRP) (Weisblat et al. 1978); or (2) introduction of a marker gene by infection with limiting dilutions of a replication incompetent retrovirus (Sanes et al. 1986; Turner and Cepko, 1987). Because the classification of a group of retrovirally-labelled cells as clonal requires that the marked cells remain somewhat coherent, retroviral markers generally are not appropriate for a widely dispersing cell type such as the neural crest (reviewed by Lumsden, 1989). However, this approach can be useful when the proper caveats are applied (cf. Frank and Sanes, 1991). Intracellular microinjection of vital fluorescent dyes or HRP offers an alternate and direct method for labelling individual cells and their progeny in the developing vertebrate nervous system (Wetts and Fraser, 1988; Holt et al. 1988). Furthermore, the fluorescent dye can be observed in living cells, permitting confirmation that only a single cell was labelled and the location of that cell in the embryo at a variety of developmental stages (cf. Wetts and Fraser, 1988).

To analyze the developmental potential of individual neural crest cells or their precursors, we have microinjected a vital dye, lysinated rhodamine dextran (LRD), intracellularly into the dorsal portion of the neural tube, containing premigratory neural crest cells (Bronner-Fraser and Fraser, 1988, 1989), or into the somitic sclerotome containing migrating neural crest cells (Fraser and Bronner-Fraser, 1991).

\section{Cell lineage of premigratory neural crest cells}

Immediately after labelling a single dorsal neural tube cell, the labelled cell had a columnar morphology and it was not possible to distinguish premigratory neural crest cells from other neural tube cells (Fig. 2A). By one day after injection, some of the progeny of the labelled cell had emigrated from the neural tube and were clearly recognizable as neural crest cells (Fig. 2B). To analyze the derivatives arising from labelled premigratory neural crest cells, embryos were allowed to survive for up to two days after injection (total incubation time of 4.5 days), by which time neural crestderived dorsal root and sympathetic ganglia had formed. The phenotypes of the descendants that inherited the LRD from the injected cells were evaluated, based upon their position, morphology, and neurofilament expression.

By two days after injection, the LRD-labelled clones contained from 2 to 73 cells, which were distributed bilaterally in about one-third of the embryos. Individual labelled precursors gave rise to both sensory and sympathetic neurons (neurofilament-positive), cells with the morphological characteristics of Schwann cells (Fig. 3) or pigment cells (neurofilament-negative), and other non-neuronal cells (neurofilament-negative; Table 1). Furthermore, analysis of neurofilament immunoreactivity demonstrated that a single labelled precursor contributed to both neural crest- and neural tube-derived neurons (Fig. 3). These data show that:

Table 1. Distribution of neurofilament-immunoreactive cells in LRD-labelled clones contributing to the neural crest

\begin{tabular}{|c|c|c|c|c|c|c|c|c|c|c|c|c|c|}
\hline \multirow[b]{2}{*}{ Class } & \multirow{2}{*}{$\begin{array}{c}\text { No. } \\
\text { embryos }\end{array}$} & \multicolumn{2}{|c|}{ NT } & \multicolumn{2}{|c|}{ DRG } & \multicolumn{2}{|c|}{ VR } & \multicolumn{2}{|c|}{ SG } & \multicolumn{2}{|c|}{ Adrenal } & \multicolumn{2}{|c|}{ PIGM } \\
\hline & & + & - & + & - & + & - & + & - & + & - & + & - \\
\hline 1 & 2 & & & $X$ & $X$ & & & & & & & & \\
\hline 2 & 6 & $\mathrm{X}$ & $\mathrm{X}$ & $X$ & $X$ & & & & & & & & \\
\hline 3 & 1 & $\mathrm{X}$ & $\mathrm{X}$ & & $X$ & & & & & & & & \\
\hline 4 & 1 & $X$ & & $X$ & $X$ & & & & & & & & \\
\hline 5 & 1 & $\mathrm{X}$ & $\mathrm{X}$ & $X$ & & & & & & & & & \\
\hline 6 & 1 & & & $X$ & $X$ & & $X$ & & & & & & \\
\hline 7 & 1 & & & & & & $\mathrm{X}$ & $\mathrm{X}$ & $\mathrm{X}$ & & & & \\
\hline 8 & 1 & & & $X$ & $X$ & & & $\mathrm{X}$ & & & & & \\
\hline 9 & 1 & & & & $X$ & & $\mathrm{X}$ & $\mathrm{X}$ & $\mathrm{X}$ & & & & \\
\hline 10 & $2^{*}$ & & & $\mathrm{X}$ & $X$ & & $x$ & $\mathrm{X}$ & $\mathrm{X}$ & & & & \\
\hline 11 & 1 & & & & $X$ & & & $\mathrm{X}$ & $\mathrm{X}$ & $\mathrm{X}$ & & & \\
\hline 12 & 2 & & $\mathrm{X}$ & $\mathrm{X}$ & $X$ & & & & & & & & $\mathrm{X}$ \\
\hline 13 & 1 & & $\mathrm{X}$ & $X$ & $\mathrm{X}$ & & $x$ & $X$ & $\mathrm{X}$ & & & & \\
\hline 14 & 1 & & $\mathrm{X}$ & $X$ & $\mathrm{X}$ & & $\mathrm{X}$ & & & & & & $\mathrm{X}$ \\
\hline 15 & 1 & $X$ & $\mathrm{X}$ & $\mathrm{X}$ & $\mathrm{X}$ & & $\mathrm{X}$ & $\mathrm{X}$ & $\mathrm{X}$ & & & & \\
\hline \multirow[t]{2}{*}{16} & 1 & & $\mathrm{X}$ & $X$ & $\mathrm{X}$ & & $\mathrm{X}$ & $X$ & $\mathrm{X}$ & $\mathrm{X}$ & & & \\
\hline & \multicolumn{13}{|l|}{ Total $=24$} \\
\hline \multicolumn{14}{|c|}{$\begin{array}{l}\text { + indicates the presence of neurofilament positive, LRD-labelled cells. } \\
\text { - indicates the presence of neurofilament negative, LRD-labelled cells. } \\
\text { * One clone in each group was derived from an emigrating cell. } \\
\text { NT=neural tube. } \\
\text { DRG=dorsal root ganglia. } \\
\text { VR=ventral root. } \\
\text { SG=sympathetic ganglia. } \\
\text { Adrenal=adrenomedullary site. } \\
\text { PIGM=prepigment cells underneath the ectoderm. }\end{array}$} \\
\hline
\end{tabular}


(1) premigratory neural crest cells have the ability to assume multiple fates in neural crest derivatives; and (2) the neural crest is not a segregated population in the neural tube, but shares a common lineage with some neural tube cells.

\section{Cell lineage of migrating neural crest cells}

The finding that some premigratory trunk neural crest cells give rise to descendants with distinct phenotypes in multiple neural crest derivatives is consistent with the idea that neural crest cells are multipotent prior to their emigration from the neural tube. This suggests that they must become restricted in phenotype after emigration from the neural tube either during their migration or at their sites of localization. To distinguish between these possibilities, we assessed the developmental potential of trunk neural crest cells after their emigration from the neural tube and as they migrated through the somite (Fig. 4). Individual cells were injected as they migrated lateral to the neural tube or within the sclerotome. Embryos were allowed to develop for two days, by which time the LRD-labelled clones contained from 2 to 67 cells, which were distributed unilaterally in all embryos. Most clones were confined to a single segment, though a few contributed to sympathetic ganglia over two segments. A majority of the clones gave rise to cells in multiple neural crest derivatives. Individual migrating neural crest cells gave rise to both sensory and sympathetic neurons (neurofilament-positive; Fig. 4), as well as cells with the morphological characteristics of Schwann cells, and other nonneuronal cells (both neurofilament-negative). Even those clones contributing to only one neural crest derivative often contained both neurofilament-positive and neurofilament-negative cells. Our data demonstrate that migrating trunk neural crest cells can be multipotent, giving rise to cells in multiple neural crest derivatives, and contributing to both neuronal and nonneuronal elements within a given derivative. Thus, restriction of neural crest cell fate must occur relatively late in migration or at the final sites of neural crest cell localization.

While these experiments clearly demonstrate that some migrating neural crest cells are multipotent, they cannot rule out the possibility that some neural crest cells are more restricted or even predetermined in their prospective fates. We observed some clones in which labelled neural crest cells populated a single neural crest derivatives. Although these clones contained both neuronal and non-neuronal cells, the non-neuronal cells may later differentiate into neurons. On the other hand, in those clones that populated more that one derivative, it is possible that some clonally-related cells would be eliminated by cell death, which occurs between days 4.5 and 9.5 in the dorsal root ganglion (Hamburger and Levi-Montalcini, 1949; Carr and Simpson, 1978). The possibility that cell death later restricts the range of phenotypes is made less likely by the experiments of Frank and Sanes (1991), who labelled premigatory neural crest cells within the neural tube with a recombinant retrovirus containing the lac $Z$ gene. Because the marker in their study is not diluted by cell division, their analysis could be carried out to a much later stage of development, after the phase of cell death. Their results using a retroviral marker confirm our findings using an injectable tracer; both approaches show that many premigratory neural crest cells give rise to multiple cell types (many types of neurons and well as non-neuronal cells) even within a single dorsal root ganglion.

If early migrating neural crest cells are multipotent, when do these cells become 'restricted' in developmental potential. Most ventrally migrating neural crest cells pass through the somitic milieu; because the entire population is exposed to similar environmental cues, it may not be surprising that migrating neural crest cells are as yet uncommitted to a particular fate. Those cells remaining adjacent to the somite and neural tube condense to form dorsal root ganglia, whereas those migrating further ventrally populate the sympathetic ganglia, aortic plexuses and adrenal medulla. Once reaching the level of the dorsal aorta, there is evidence that neural crest-derived cells become partially restricted (Doupe et al. 1985; Anderson and Axel, 1986) to the 'sympathoadrenal' sublineage (precursors to sympathetic neurons, small intensely fluorescent cells, and adrenomedullary cells; Landis and Patterson, 1981). The existence of such partially restricted populations is consistent with the notion that initially multipotent cells become more limited in developmental potential at late migratory stages or at their final destinations.

\section{Importance of the time of neural crest cell emigration from the neural tube in determination of cell fate}

Neural crest cells and/or the migratory paths available to them may change during the course of their migration and the occupation of their derivatives. Thus, the time at which neural crest cells exit the neural tube may contribute to the range of derivatives available to them. To test this idea, Weston and Butler (1966) transplanted tritiated thymidine-labelled neural tubes from the trunk region of 'older' avian embryos to trunks of 'younger' hosts (Weston and Butler, 1966). They found that the neural crest cells emerging from both the older and young neural tubes could give rise to the same range of neural crest derivatives. In contrast, neural crest cells emerging from 'young' neural tubes transplanted to 'older' embryos contributed only to dorsal derivatives, such as dorsal root ganglia and pigment cells.

Using the lipophilic vital dye, DiI, we have confirmed that neural crest cells have an orderly pattern of migration (Serbedzija et al. 1989). DiI was injected into the neural tube prior to neural crest cell migration; this procedure labels all neural tube cells including any premigratory neural crest cells. When neural tubes of 'young' embryos are labelled, the DiI-labelled neural 

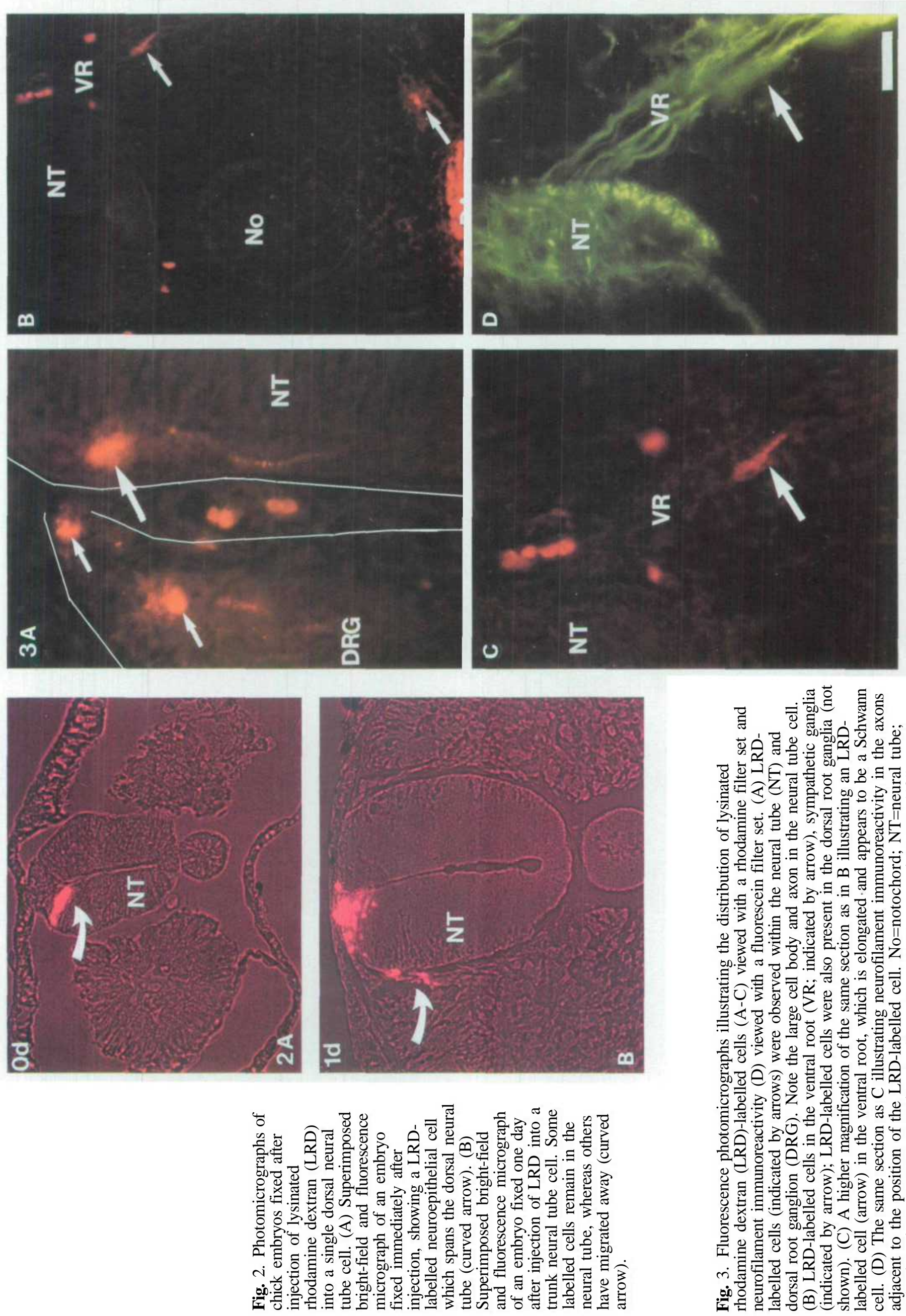

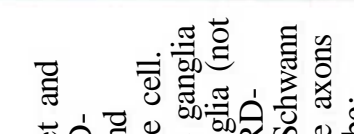

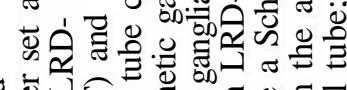

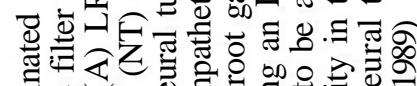

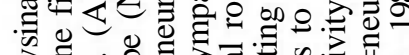

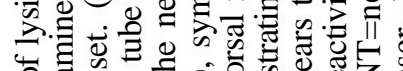
प्ष

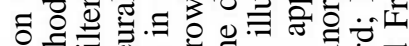

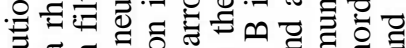

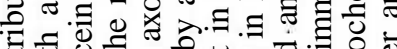

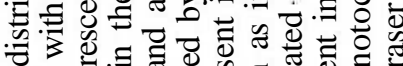
ช

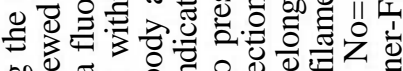
60.0

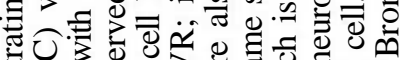

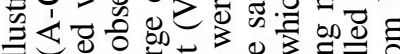

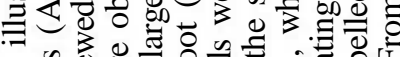

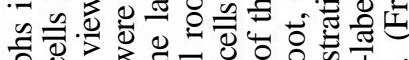

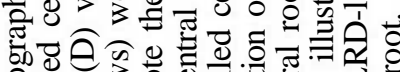

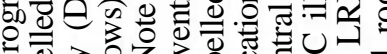

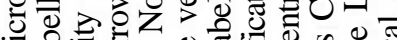

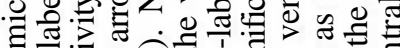

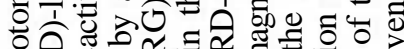

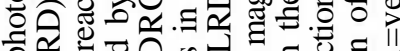

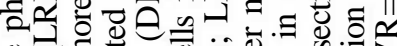
8

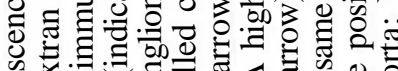

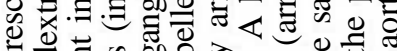

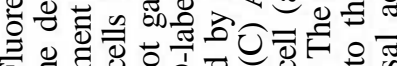

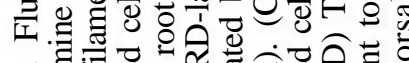

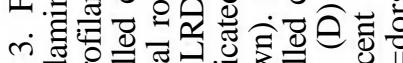
응 

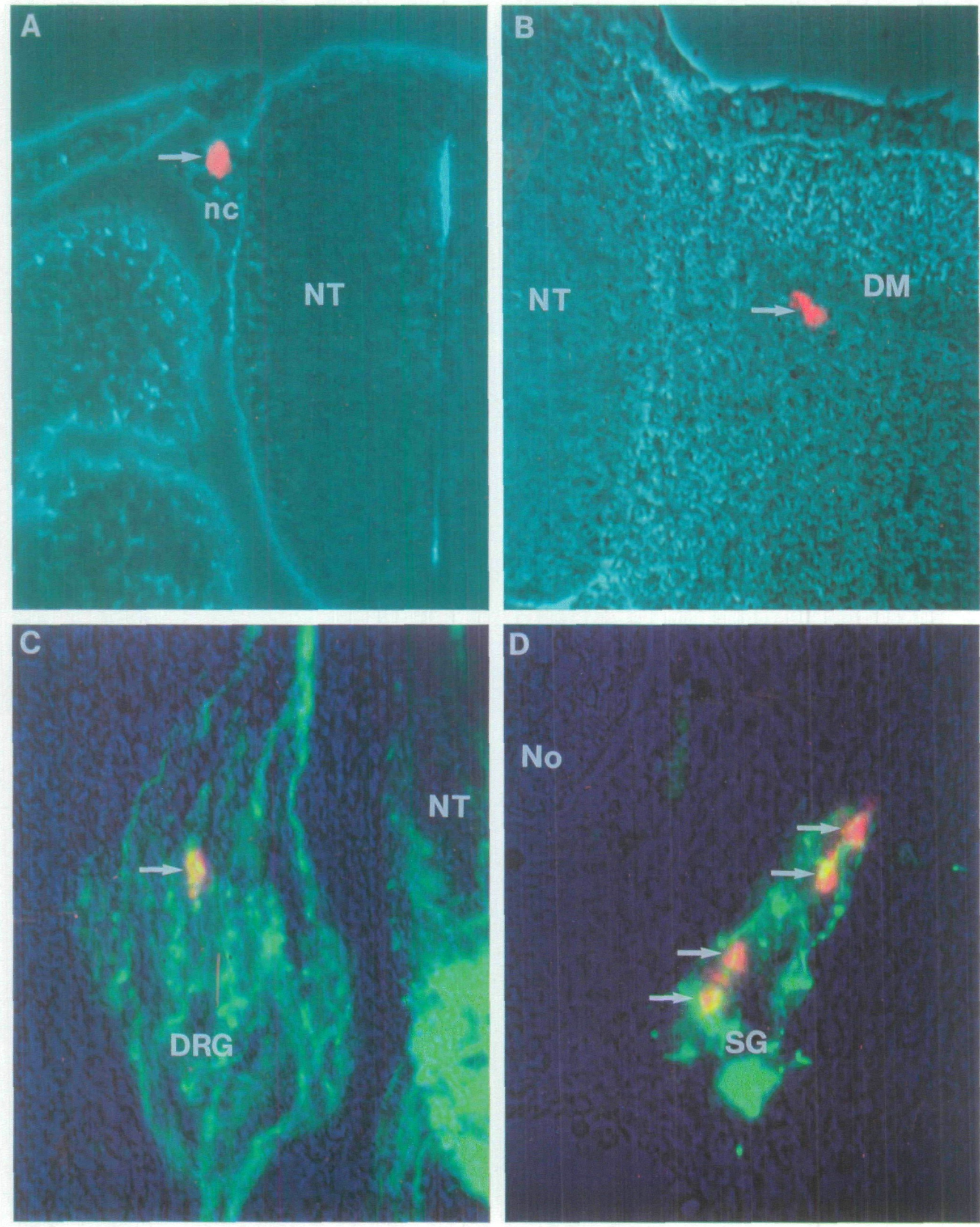

Fig. 4. Chick embryos fixed shortly after injection (A and B) of lysinated rhodamine dextran (LRD; red) into migrating neural crest cells or after two additional days of incubation (C and D) followed by neurofilament staining (green). (A) An LRD-labelled cell (arrow) within a stream of migrating neural crest cells (nc) adjacent to the neural tube (NT). (B) An LRD-labelled migrating neural crest cell (arrow) within the rostral portion of the sclerotome. (C) A neurofilamentimmunoreactive neuron (arrow) in the dorsal root ganglion (DRG; in this embryo, LRD-labelled cells were observed in the DRG, sympathetic ganglion (SG), and ventral root. (D) Neurofilament-immunoreactive cells (arrows) in the SG of an embryo that contained LRD-labelled cells in sympathetic and adrenomedullary cells. No=notochord; $\mathrm{DM}=$ Dermomyotome. 


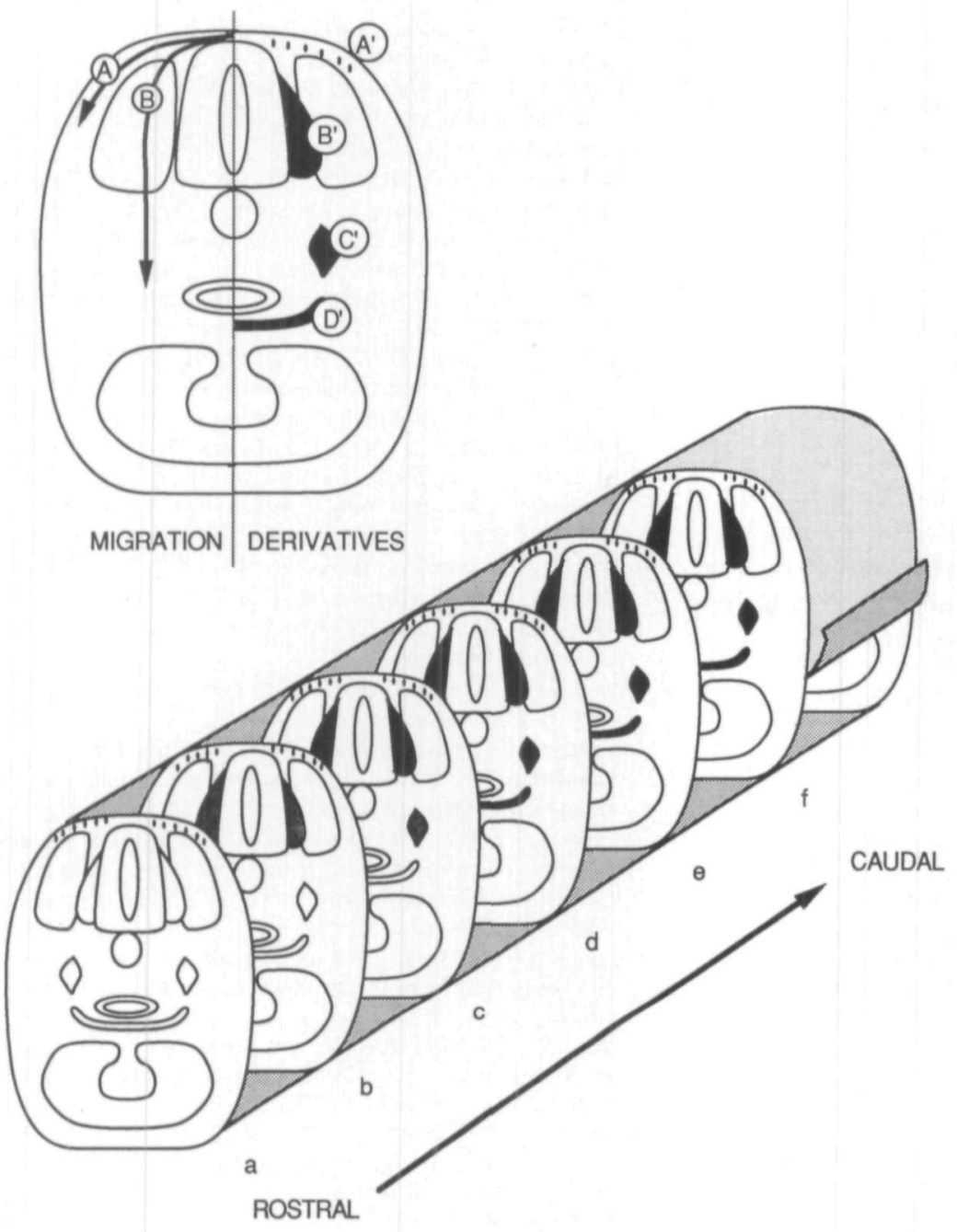

Fig. 5. A schematic representation of the rostral to caudal distribution of DiI in the neural crest derivatives of a single embryo injected at stage 19 and fixed at stage 21 . a-f represents levels along the rostrocaudal axis from which transverse sections were taken. (a) At the level of the 9th somite, DiI-labelled cells were observed along the dorsolateral pathway. (b) At the level of the 15 th somite, DiI-labelled cells were observed along the dorsolateral pathway and in the dorsal root ganglia. (c) At the level of the 22nd somite, DiI-labelled cells were seen along the dorsolateral pathway, in the dorsal root ganglia, and in the sympathetic ganglia. (d-f) From the level of the 38th somite to the caudal end of the embryo, DiIlabelled cells were observed in all truncal neural crest derivatives. (From Serbedzija et al. 1989) crest cells subsequently migrate out of the neural tube to form dorsal root and sympathetic ganglia, adrenomedullary cells and chromaffin cells. By injecting DiI at progressively later stages of development, we labelled only those neural crest cells that were premigratory at the time of injection. Later emigrating cells were found to contribute to progressively more dorsal derivatives (Fig. 5). Thus, the contribution of neural crest cells to their derivatives becomes restricted in a ventral-todorsal order. The last cells to exit the neural tube are precursors to pigment cells, which migrate dorsolaterally under the ectoderm (Serbedzija et al. 1989). This orderly pattern of migration may restrict the range of derivatives open to later emigrating neural crest cells, though other factors also could contribute to restriction of these cells' fate.

\section{Conclusion}

An idea of cell lineage segregation in the trunk neural crest can be inferred from the present results in combination with previous studies. The majority of premigratory and early migrating neural crest cells appear to be multipotent in their developmental potential. Intermingled with these multipotent cells, there may be minority populations that are more restricted or predetermined in developmental potential. Either during late stages of migration or at their final sites of localization, the multipotent precursors become fully or partially committed. In the case of cells around the dorsal aorta, they appear to be restricted to the sympathoadrenal sublineage prior to final commitment to a single phenotype. The choice of sublineage or final cell fate may be in part stochastic and in part influenced by signals present in the external environment. One exogenous factor may be timing of emigration from the neural tube, which bears on the range of sites of localization available to neural crest cells (Serbedzija et al. 1989). Thus, not only cell lineage, but the timing, position and pathway of a migrating neural crest cell may influences the choice of cell fate.

Factors present in the local environment of migrating neural crest cells, including tissues (Cohen, 1972; Norr, 1973), extracellular matrix molecules (Maxwell and Forbes, 1987, 1990; Perris et al. 1988) and growth factors (Birren and Anderson, 1990; Kalcheim et al. 1987), may influence phenotypic decisions. For example, regionally restricted growth factors may be produced by selected tissues and/or associated with the extracellular matrix. There is some indication that fibroblast growth factor (FGF) affects early neural crest 
cells (Birren and Anderson, 1990) and that brainderived neurotrophic factor (BDNF) may be important for the survival of neural crest precursors to dorsal root ganglion neurons (Kalcheim et al. 1987). These findings are consistent with the possibility that localized accumulation of tissue derived factors may influence neural crest cell lineage decisions in a region-specific manner.

The neural crest is a particularly intriguing system because of the diversity of cell types arising from an apparent homogeneous population of precursors. The advent of new techniques such as cell marking by lineage tracers and retroviruses, clonal analysis in vitro, and the availability of neural crest-derived cell lines has been invaluable to the study of neural crest cell lineage. These approaches promise to give new insights into the mechanisms of cell type segregation in this fascinating population of cells.

This work was supported by USPHS (HD-25138).

\section{References}

Anderson, D. J. AND Axel, R. (1986). A bipotential neuroendocrine precursor whose choice of cell fate is determined by NGF and glucocorticoids. Cell 47, 1079-1090.

Baroffio, A., Dupin, E. and LeDouarin, N. M. (1988). Cloneforming ability and differentiation potential of migratory neural crest cells. Proc. natn. Acad. Sci. U.S.A. 85, 5325-5329.

Baroffio, A., Dupin, E. and LeDouarin, N. M. (1991). Common precursors for neural and mesectodermal derivatives in the cephalic neural crest. Development 112, 301-306.

BirRen, S. J. AND ANDERSON, D. J. (1990). A v-myc-immortalized sympathoadrenal progenitor cell line in which neuronal differentiation is initiated by FGF but not NGF. Neuron 4 , 189-201.

Bronner-Fraser, M. (1986). Analysis of the early stages of trunk neural crest migration in avian embryos using the monoclonal antibody HNK-1. Devl Biol. 115, 44-55.

Bronner-Fraser, M. and Fraser, S. (1988). Cell lineage analysis shows multipotentiality of some avian neural crest cells. Nature $335,161-164$

Bronner-Fraser, M. and Fraser, S. (1989). Developmental potential of avian trunk neural crest cells in situ. Neuron 3 755-766.

Bronner-Fraser, M. E., Sieber-Blum, M. and Cohen, A. M. (1980). Clonal analysis of the avian neural crest: Migration and maturation of mixed neural crest clones injected into host chicken embryos. J. comp. Neurol. 193, 423-434.

Carr, V. and Simpson, S. B. (1978). Proliferative and degenerative events in the early development of chick dorsal root ganglia. I. Normal development. J. comp. Neurol. 182 , 727-740.

Cohen, A. M. (1972). Factors directing the expression of sympathetic nerve traits in cells of neural crest origin. J. exp. Zool. 179, 167-182.

Doupe, A. J., Landis, S. C. And Patterson, P. H. (1985). Small intensely fluorescent cells in culture: role of glucocorticoids and growth factors in their development and interconversions with other neural crest derivatives. J. Neurosci. 5, 2143-2160.

Frank, E. AND Sanes, J. R. (1991). Lineage of neurons and glia in chick dorsal root ganglia: analysis in vivo with a recombinant retrovirus. Development 111, 895-908.

Fraser, S. E. And Bronner-Fraser, M. (1991). Migrating neural crest cells in the trunk of the avian embryo are multipotent. Development 112, 913-920.

Gimlich, R. L. ANd Braun, J. (1986). Improved fluorescent compounds for tracing cell lineage. Dev/ Biol. 109, 509-514.

Hamburger, V. and Levi-Montalcini, R. (1949). Proliferation, differentiation and degeneration in the spinal ganglia of the chick embryo under normal and experimental conditions. J. exp. Zool. 111, 457-501.

Holt, C., Bertsch, T. W., Ellis, H. M. and Harris, W. A. (1988). Cellular determination in the Xenopus retina is independent of lineage and birth date. Neuron 1, 15-26.

Kalcheim, C., Barde, Y.-A., Thoenen, H. and LeDouarin, N. M. (1987). In vivo effect of brain-derived neurotrophic factor on the survival of developing dorsal root ganglion cells. EMBO J. 6, 2871-2873.

Landis, S. C. and Patterson, P. H. (1981). Neural crest cell lineages. Trends Neurosci. 4, 172-175.

LeDouarin, N. M. (1982). The Neural Crest. Cambridge University Press, N.Y.

LumSDEN, A. G. S. (1989). Multipotent cells in the avian neural crest. Trends Neurosci. 12, 81-83.

Maxwell, G. D. And Forbes, M. E. (1987). Exogenous basement membrane-like matrix stimulates adrenergic development in avian neural crest cultures. Development 101, 767-776.

Maxwell, G. D. and Forbes, M. E. (1990). The phenotypic response of cultured quail trunk neural crest cells to a reconstituted basement membrane-like matrix is specific. Devl Biol. 141, 233-237.

NorR, S. C. (1973). In vitro analysis of sympathetic neuron differentiation from chick neural crest cells. Devl Biol. 34, 16-38.

Perris, R., von Boxberg, Y. and LöfBerg, J. (1988). Local embryonic matrices determine region-specific phenotypes in neural crest cells. Science 241, 86-89.

Rickmann, M., Fawcett, J. W. and Keynes, R. J. (1985). The migration of neural crest cells and the growth of motor axons through the rostral half of the chick somite. J. exp. Morph. Embryol. 90, 437-455.

Sanes, J. R., Rubenstein, J. L. R. and Nicolas, J.-F. (1986) Use of a recombinant retrovirus to study postimplantation lineage in mouse embryos. EMBO J. 5, 3133-3142.

Serbedzija, G., Bronner-Fraser, M. and Fraser, S. E. (1989) Vital dye analysis of the timing and pathways of avian trunk neural crest cell migration. Development 106, 806-816.

Sieber-Blum, M. (1989). Commitment of neural crest cells to the sensory neuron lineage. Science 243, 1608-1611.

Sieber-Blum, M. And Cohen, A. M. (1980). Clonal analysis of quail neural crest cells: they are pluripotent and differentiate in vitro in the absence of non-crest cells. Devl Biol. 80, 96-106.

Turner, D. L. And Cepko, C. L. (1987). A common progenitor for neurons and glia persists in rat retina late in development. Nature 328, 131-136.

WetTS, R. AND Fraser, S. E. (1988). Multipotent precursor cells can give rise to all major cell types of the frog retina. Science 239, 1142-1145.

Weisblat, D. A., Sawyer, R. T. and Stent, G. S. (1978). Cell lineage analysis by intracellular injection of a tracer enzyme. Science 202, 1295-1298

Weston, J. A. And Butler, S. L. (1966). Temporal factors affecting the localization of neural crest cells in chick embryos. Devl Biol. 14, 246-266. 